\title{
PALLIATIVE CARE ETHICS
}

\author{
NURUNNABI ASM
}

\begin{abstract}
:
Palliative care is the active total care of patients whose disease is not responsive to curative treatment. Hence, palliative care is a system of treatment which is administered to the patients suffering from chronic illness to ease their pain, stress and symptoms of the disease. As it is a comfort care given to the patients at the last stage of their lives, it is related to many ethical issues and concerns. The Palliative Care Ethics depends on the values and beliefs of all involved in administering palliative care. Its framework is actually based on the moral values and principles of the professionals involved, patients concerned, their families and the society as a whole. Palliative care is a very sensitive issue. It is a blessing, indeed, if it is rendered in the appropriate manner. The basic principle on which palliative care revolves is the dignity and value of life. It is basically a philosophy of care for the patient. As it aims at relieving the pain and stress of the patient and his/her family, it should not be too professionalized and moneyoriented. It is a service, which is rendered for those waiting for the end of their lives. Therefore, it should be based on love, sympathy, care and concern.
\end{abstract}

Key words: Palliative care, patient care, patients' needs, ethical issues.

J Dhaka Med Coll. 2011; 20(1) : 199-203.

\section{Introduction:}

Palliative care is an interdisciplinary therapeutic model that focuses on the comprehensive management of the physical, psychological, social and spiritual needs of patients with progressive incurable illnesses and their families ${ }^{1}$. The model applies throughout the course of the illness, and includes an array of interventions that are intended to maintain the quality of life, or attenuate the suffering, of the patient and family ${ }^{2}$. As death approaches, palliative care must intensify and ensure that comfort is a priority, practical needs are addressed, psychosocial and spiritual distress is managed, values and decisions are respected, and opportunities are available for growth and resolution ${ }^{1}$. The World Health Organization defines that "Palliative care is the active total care of patients whose disease is not responsive to curative treatment. Control of pain, of other symptoms, and of psychological, social and spiritual problems is paramount. The goal of palliative care is the achievement of the best possible quality of life for patients and their families." 2

The definition of palliative care has much in common with hospice. In the United States, however, palliative care is evolving in a way that goes well beyond the American version of hospice $^{3}$. Palliative care aims to address the physical, psychosocial, and spiritual concerns that contribute to both the quality of life and quality of dying for patients with lifethreatening illnesses at any phase of the disease. Although the focus intensifies at the end of life, the core issues ${ }^{-}$comfort and function ${ }^{-}$defined broadly and evaluated within the context of the family, are important throughout the course of the disease ${ }^{4}$. For the many patients with incurable and progressive diseases who are undergoing active lifeprolonging therapies and have life expectancies that potentially extend to years, palliative care includes symptom management, therapy aimed at restoring function, practical support, and psychological interventions. At all stages of the disease, effective palliative care increases the likelihood that the patient will cope adequately with the rigors of therapy and maintain a satisfying level of physical and psychosocial functioning 5 . For the dying patient, optimal palliative care addresses the traditional concerns of the hospice movement. Comfort for the patient and preparation of both the patient and family for the inevitability of dying are often

Correspondence : Dr. Abu Sadat Mohammad Nurunnabi, Lecturer, Department of Anatomy, Dhaka Medical College, Dhaka. Cell Phone: +8801712290608, Email: shekhor19@yahoo.com 
the overriding challenges in this setting. This preparation may have to address a broad range of psychological, social, family, and spiritual concerns ${ }^{6}$.

The word 'ethics' is derived from the Greek word 'ethos', which means the character, spirit and attitudes of a group of people or culture. Ethics may be defined as the set of moral values and principles that distinguish what is right from what is wrong. Ethics has two objectives ${ }^{-}$it evaluates human practices by calling upon moral standards and it may give prescriptive advice on how to act morally in a given situation ${ }^{7}$. Ethics, therefore, aims to study both moral and immoral behavior in order to make well-founded judgments and to arrive at adequate recommendations. Ethical codes of different professions guide professionals to maintain professional standard acceptable to the stakeholders and people in the society ${ }^{6,7}$.

Importance of Palliative Care as a Discipline:

Palliative care has numerous key concepts, which include its aim to ${ }^{8}$ :

- $\quad$ affirm life and regards dying as normal;

- integrate the psychological and spiritual aspects of care;

- offer comprehensive support to promote quality of life;

- offer support systems to help patients live as actively as possible until death.

Whereas the number of palliative care services is increasing rapidly in the affluent world ${ }^{9,10}$, the extent of establishment in developing countries remains at a poor level ${ }^{10,11}$. In Bangladesh, the concept of palliative care is known to the physician community. However, the concept of Palliative Medicine is little known or appreciated. More than a million people die in Bangladesh every year. Approximately 0.6 million of them are estimated to be in need of palliative care service. More than $4 \%$ of the population are aged 65 and above and the number of elderly are on a steady rise. Most of these people are in need of care routinely offered by a palliative care services ${ }^{12}$.
According to the World Health Organization ${ }^{2}$, palliative care:

- provides relief from pain and other distressing symptoms;

- affirms life and regards dying as a normal process;

- intends neither to hasten or postpone death;

- integrates the psychological and spiritual aspects of patient care;

- offers a support system to help patients live as actively as possible until death;

- offers a support system to help the family cope during the patients illness and in their own bereavement;

- uses a team approach to address the needs of patients and their families, including bereavement counselling, if indicated;

- will enhance quality of life, and may also positively influence the course of illness;

- is applicable early in the course of illness, in conjunction with other therapies that are intended to prolong life, such as chemotherapy or radiation therapy, and includes those investigations needed to better understand and manage distressing clinical complications.

\section{Palliative Care Ethics:}

Palliative care is a system of treatment which is administered to patient's suffering from acute illness to ease their pain, stress and symptoms of disease. As it is a comfort care administered to patient's nearing the end of their life, it poses many ethical issues and concerns ${ }^{6}$. Like any other medical care service, palliative care ethics has got four basic components of ethical practice ${ }^{-}$respect to patients' autonomy, beneficence, non-maleficence, and justice ${ }^{6}$. Many ethical dilemmas occur when working in palliative care and the confusion or conflict around advanced care planning is one issue where ethical dilemmas occur. As the philosophy of palliation is increasingly recognized to be important in health care delivery system, the concern about palliative care ethics has been much increased ${ }^{13,14}$. The 
main important ethical issues are discussed here:

\section{Respect to the patients' autonomy:}

Palliative care should focus on improving the quality of life of the patient and his family. It should also recognize the privacy, autonomy and priority of the patient and his family ${ }^{13-20}$. Though it can make suggestions regarding the course of treatment and the methods to be followed while undergoing medical procedures, it should recognize the patient's freedom in making decisions ${ }^{14,16,17,20}$. Personal consent of the patient to any medical procedure should be voluntary, competent and informed. Since palliative care patients are in a weakened state, they may give consent without fully understanding the situation. The doctor should seek consent from the patient in a responsible, sensitive and caring manner ${ }^{14,18-20}$. The service providers should also respect the individuality of the patient. Whatever be the patient's condition, he is an individual. It is his life and he has the full freedom of choice. $\mathrm{He}$ is the owner of his life. Hence, it is the patient and his needs that are of utmost importance at any point of time and palliative care should only assist the patient and his family in living their lives ${ }^{6,21}$. They should not take over the charge of controlling the lives of the patient and his family.

\section{Beneficence:}

This implies that we should always do the best for our patients. However, it also implies that we as individual professionals have the skills and expertise to deal with the problems, and wisdom to refer the patient to someone else, if we already have not ${ }^{6,22}$. That is a doctor should act in the best interest of the patients ${ }^{23}$.

\section{Non-maleficence:}

It seems most appropriate at the first sight. We should not do anything which may cause a potential harm to the patient. However, in practice it is more difficult to judge ${ }^{15,18}$. Much of what we do, for example, in cancer treatment is potentially harmful, and the benefit might not always be clear ${ }^{22}$. Still we do all those in good faith to give better treatment and relieve the patient from pain and other symptoms.

\section{Justice:}

This implies fairness for all and equity and equality of care $^{22}$. Legal aspects and human rights give the fundamental protections that allow equal participation and individual justice in a society ${ }^{24}$. In the $21^{\text {st }}$ century, the right to healthcare is well-established, encompassing not only the delivery of basic clinical services, but also an environment to ensure good health for all in each sphere ${ }^{25}$. There arise some problems like euthanasia (where the patient seeks to end his/her life, especially in incurable, chronic, painful diseases like cancer) ${ }^{26-28}$. Though the practice of euthanasia is legalized in some countries (the Netherlands, Belgium, some states of USA and Australia) ${ }^{23}$, it poses an ethical dilemma in palliative care strategy ${ }^{27,28}$.

\section{Humanitarian View:}

The basic principle on which palliative care revolves is the dignity and value of life ${ }^{19-21}$. It is basically a philosophy of care for the patient. As it aims at relieving the pain and stress of the patient and his family, it should not be too professionalized and money-oriented. It is a service, a service for those nearing the end of life. Therefore, it should be based on love, sympathy, care and concern.

Of course, sometimes we have no right answer to those dilemmas of our service. Here, the boundaries within which our decisions must lie should be learned. A knowledge of the relevant laws helps, as does having a framework for ethical decision-making ${ }^{22-26}$. There is also a need to recognize the cultural influences on decision-making ${ }^{12,13,25}$. Finally, honesty to oneself is important; when all is said and done, we need to live with the consequences of our decisions ${ }^{16,19,29}$. So as said by Hippocrates, "The purpose of medicine is to do away with the sufferings of the sick, to lessen the violence of the disease and to refuse to treat those who are overmastered by their disease." These points are especially important for the discipline of Palliative Medicine ${ }^{29,30}$.

\section{Conclusion:}

The Palliative Care Ethics depends on the values and beliefs of all involved in 
administering palliative care. Its framework is actually based on the moral values and principles of the professionals involved, patients concerned, their families and the society as a whole. Palliative care is a very sensitive issue. Health care professionals need to focus on the physical, psychosocial, and spiritual well-being of the dying patients and provide culture-sensitive care in order to ensure a high quality of life and a 'good death'13,31-33. It is a blessing if it is rendered in the appropriate manner. Once Dame Cicely Saunders, the founder of the Modern Hospice Movement, said, "How people die remains in the memory of those who live on". We should not let the memories be bitter in taste and shatter in experience. And above all, during dealing with the patients the physicians should remember only the word, 'empathy, empathy and empathy'.

\section{Acknowledgement:}

I would like to pay my gratitude to Prof. Nezamuddin Ahmad, Project Coordinator, Palliative Care Service, Bangabandhu Sheikh Mujib Medical University, Prof. Shamim Ara, Head of the Department of Anatomy, Dhaka Medical College, and Prof. M. Ekhlasur Rahman, Head of the Department of Paediatrics, Dhaka Medical College \& Hospital, Dhaka, for their sincere guidance and enormous cooperation in preparation of this article.

(This article is based on the oral presentation of the author in the $2^{\text {nd }}$ International Conference on Palliative Care and Public Health 2011, jointly organized by Bangabandhu Sheikh Mujib Medical University, Dhaka, Bangladesh, Institute of Palliative Medicine, Kerala, India, and University of Bath, U.K., held on 21-23 January, 2011 at Hotel Sheraton, Dhaka).

\section{References:}

1. Department of Health. UK. End of Life Care Strategy: Second Annual Report. 2010. Available from: http://www.dh.gov.uk/en/ Publicationsandstatistics / Publications / Publications PolicyAndGuidance/DH_1 18810 [Accessed on 10. 12. 2010].

2. World Health Organization. Technical Report Series 804, Cancer Pain and Palliative Care.
Geneva: World Health Organization (WHO). 1990: 11 .

3. National Cancer institute at the National Institutes of Health, USA. Available from: http:// www.cancer.gov/cancertopics / factsheet/ Support/hospice [Accessed on 10. 12. 2010].

4. Clark D. Between hope and acceptance: the medicalisation of dying. BMJ 2002; 324: 905-7.

5. Werth JL Jr., Gordon JR, Johnson RR Jr. Psychosocial issues near the end of life. Aging Ment Health 2002; 6: 402-12.

6. Beauchamp TL, Childress JF. Principles of biomedical ethics. $5^{\text {th }}$ ed. New York: Oxford University Press; 2001.

7. Hossain MK, Karim MS, Islam S. A comparative analysis of Conventional Ethical Code and Islamic Ethical Code in accounting profession. Thoughts on Economics 2010; 20(1): 39-53.

8. World Health Organization. The Ottawa Charter for Health Promotion. Geneva: World Health Organization (WHO). 1986.

9. Centeno C, Clark D, Rocafort J, Flores LA, Lynch $\mathrm{T}$, Praill D, et al. The map of specific resources of palliative care in Europe. [Abstract]. Palliat Med 2006; 20: 316.

10. Sepúlveda C, Marlin A, Yoshida T, Ullrich A. Palliative care the World Health Organization's global perspective. J Pain Symptom Manage 2002; 24: 91-6.

11. Bruera E, Sweeney C. Palliative care models: International perspective. J Palliative Med 2002; 5: 319-43.

12. Rahman AKMM, Ahmed N. Palliative care: we should begin to think. [Editorial]. J Bangladesh Coll Phys Surg 2011; 29(1): 1-2.

13. Bowman K. Communication, negotiation, and mediation: dealing with conflict in end of life decisions. J Palliative Care 2000; 16(Suppl): S17 S23.

14. Loseth D, Moore C, Mulder J, Peterson C. Cultural and spiritual issues. In: Kuebler K, Davis M, Moore C. eds. Palliative practices: an interdisciplinary approach. St Louis: Elsevier Mosby; 2005. p.309 34.

15. Chiu T Y, Hu W Y, Cheng S Y, Chen C Y. Ethical dilemmas in palliative care: a study in Taiwan. $\mathrm{J}$ Med Ethics 2000; 26(5): 35.

16. Maddox I. Palliative care in the $21^{\text {st }}$ century. Med J Austr 2003; 179(6): 45.

17. Woods S. Respect for persons, autonomy and palliative care. Medicine, Health Care and Philosophy 2005; 8: 24353. 
18. Coveney A. Ethical issues surrounding advanced disease. In: Kuebler K, Heidrich D, Esper P. eds. Palliative and end of life care. $3^{\text {rd }}$ ed. St Louis: Elsevier Saunders; 2007. p.63 74.

19. Barretto $Z$. Ethical issues in palliative care. Issues Med Ethics. 2003; 11(4):

20. Twycross R. Introducing palliative care. $4^{\text {th }}$ ed. Dhaka: Bersha Pvt. Ltd.; 2003. p. 8-13.

21. Randall F, Downie RS. Palliative care ethics: a companion for all specialties. $2^{\text {nd }}$ ed. New York: Oxford University Press; 1999.

22. Cherny NI. Ethical issues. In: Hanks G, Cherny NI, Christakis NA, Fallon M, Kassa S. eds. Oxford textbook of palliative medicine. $4^{\text {th }}$ ed. New York: Oxford University Press; 2005. p. 277-303.

23. Mohanti BK. Ethics in palliative care. [Editorial]. Indian J Pall Care 2009; 15(2): 89-92.

24. Peel M. Human rights and medical ethics. J Soc Med 2005; 98: 171-3.

25. Colledge NR, Walker BR, Ralston SH. eds. Davidson's principle and practice of medicine. $21^{\text {st }}$ ed. Edinburgh: Elsevier Churchill Livingstone; 2010. p.

26. British Medical Association. Medical ethics today: its practice and philosophy. London: BMA, 1993: 76.
27. Callahan D. Justice, Biomedical Progress, and Palliative Care. [Editorial]. Progress in Palliative Care 2000; 8: 3-4.

28. Davis M, Kuebler K. Palliative and end of life care perspectives. In: Kuebler K, Heidrich D, Esper P. eds. Palliative and end of life care. St. Louis: Saunders Elsevier; 2007.

29. Gatrad AR, Sheikh A. Medical ethics and Islam: principles and practice. Arch Dis Child 2001; 84: $72-5$.

30. Frager G. Palliative care and terminal care of children. Child Adolescent Psychiatr Clin North Am 1997; 6: 889-909.

31. Woods S. Respect for persons, autonomy and palliative care. Medicine, Health Care and Philosophy 2005; 8: 24353.

32. Mahtani-Chugani V, González-Castro I, de Ormijana-Hernández AS, Martín-Fernández R, de la Vega EF. How to provide care for patients suffering from terminal non-oncological diseases: barriers to a palliative care approach. Palliat Med 2010; 24: 787-95.

33. Shubha R. End-of-life care in the Indian context: the need for cultural sensitivity. Indian J Palliative care $2007 ; 13(2)$ : 59-64. 